\title{
Non-Exclusive Breast Feeding And Its Factors In The First 6-Month Life of Infants Among Mother- Infant Pairs of 6 to 12 months In Debre Tabor Town, Northwest Ethiopia, 2019: Community Based cross sectional Study.
}

Dejen Getaneh Feleke ( $\square$ dejengetaneh38@gmail.com )

Debre Tabor University

Chanyalew Worku Kassahun

University of Gondar

Tesfamichael G/Mariam W/mariam

University of Gondar

Sheganew Fetene Tassaw

Debre Tabor University

Ermiase Sisay Chanie

Debre Tabor University

\section{Research}

Keywords: Non-exclusive breast feeding, Debre Tabor Town, Ethiopia

Posted Date: September 1st, 2020

DOl: https://doi.org/10.21203/rs.3.rs-66897/v1

License: (c) (1) This work is licensed under a Creative Commons Attribution 4.0 International License. Read Full License

Version of Record: A version of this preprint was published at Heliyon on April 1st, 2021. See the published version at https://doi.org/10.1016/j.heliyon.2021.e06922. 
Non-Exclusive Breast Feeding And Its Factors In The First 6-Month Life of Infants Among Mother-Infant Pairs of 6 to 12 months In Debre Tabor Town, Northwest Ethiopia, 2019 :Community Based cross sectional Study.

Dejen Getaneh Feleke 1* (dejengetaneh38@gmail.com), Chanyalew Worku Kassahun ${ }^{2} \quad$ (chanyalewworku@gmail.com), Tesfamichael G/Mariam W/mariam², (tesfish888@gmail.com), 1 Sheganew Fetene Tassaw (sheganewabeba@gmail.com), ${ }^{1}$ Ermiase Sisay Chanie (Ermiyassisay1@gmail.com)

Authors' affiliation:

${ }^{1}$ Department of Nursing, College of Health Sciences, Debre Tabor University, P.O.BOX 272, Debre Tabor, Ethiopia.

${ }^{2}$ Department of comprehensive nursing, college of medicine and health sciences University of Gondar, P.O.BOX 196, Gondar, Ethiopia.

${ }^{2}$ Department of Surgical nursing, college of medicine and health sciences University of Gondar, P.O.BOX 196, Gondar, Ethiopia.

“Corresponding author: Lecturer of Pediatrics and Child Health Nursing @ Debre Tabor University, email: dejengetaneh38@gmail.com: P.O.Box:272, Debre Tabor University Debre Tabor, Ethiopia. 


\section{ABSTRACT}

Background: Non-exclusive breastfeeding is becoming major cause of infants and children morbidity and mortality in developing countries including Ethiopia. The magnitude of non-exclusive breast feeding and its factors is not addressed in the study area.

Objective: To assess the prevalence of non-exclusive breast feeding and its factors in the first 6 months life of infants among mother-infant pairs of 6 to 12 months in Debre Tabor Town, Northwest Ethiopia, 2019.

Methods: A Community based cross sectional study was conducted among 860 mother-infant pairs of 6 to 12 months in Debre Tabor Town, from March 1-30/2019. To select study participants cluster sampling technique was employed. Data was entered into Epi info version 7.2.0.1, and exported to SPSS window version 20 for analysis. Binary and Multivariable logistic regression was used to see the association between dependent and independent variables. Odds ratio with 95\% confidence interval was computed. P-value $\leq 0.05$ was used to declare association.

Results: The prevalence of non-exclusive breastfeeding of mothers to their infants within the first 6 months was found to be $39.8 \%(95 \% \mathrm{Cl}: 36.6-43.0)$. Mothers whose husbands had no formal education (AOR=6.60 [95\%Cl: 4.14, 10.41), primary education (AOR=4.30 [95\% Cl: 2.62, 7.20]), Mothers governmental employed $((\mathrm{AOR}=8.20$ [(95\% Cl: 5.191, 12.940]), daily laborer (AOR=1.70 [95\% Cl: 1.01, 2.90], merchant mothers (AOR=0.44 [95\% Cl: 0.35, 0.90]), and Mothers who had no postnatal care follow up for current baby in health service (AOR=2.40 [(95\% Cl: $1.56,3.76])$ were significantly associated with Non-exclusive breastfeeding within the first 6 months. Conclusion and Recommendations: High proportion of mothers practiced non-exclusive breast feeding within the first 6 months. Husband's had no formal education, primary education maternal governmental employed, daily laborer, merchant and mothers who had no post-natal follow up were predictors with outcomes in the study area. Hence; it is better to increase annual leave for delivered mothers, improve awareness of husbands towards benefits of introducing complementary feeding timely, and advice mothers to improve post-natal period follow up.

Keywords: Non-exclusive breast feeding, Debre Tabor Town, Ethiopia. III 


\section{BACKGROUND}

Non-exclusive breast feeding (NEBF) is defined as provision of food or fluids in addition to the breast milk other than drugs, vitamins and minerals to infants before the age of six months $(1,2)$. NEBF is becoming a major cause of infants and children morbidity and mortality in developing countries. It is believed to be responsible for $10 \%$ of the disease burden, $10 \%$ of the 44 million DALYs(Disability-Adjusted Life-Years), and 1.4 million child deaths (3). In addition in developing countries early and abrupt cessation of BF followed by an introduction of dirty and unsound artificial feeding of infants is a common practice than makes children more vulnerable to infection with different pathogens $(4,5)$.

No more than $35 \%$ of infants worldwide are exclusively breast Fed during the first four months of life. CF frequently begins too early or too late and foods are often nutritionally inadequate and unsafe $(2,6)$.

In Ethiopia, high numbers of mothers are practicing NEBF. It was $42 \%$ national as it was reported in 2016 Ethiopian Demographic and Health Survey (EDHS) (7), and ranged from $13 \%-60 \%$ in individual studies (8),(3),(9),(10), (11),(2).

Infants who had not been fed exclusively face future health challenges. These problems cause decrease the full absorption of nutrients from breast milk; predispose them to diarrhea, and acute respiratory infections. This further contributes to weight loss; malnutrition; poor academic performance; decreased productivity; impaired cognitive, and social development $(3),(12,13)$. But, the above problems are preventable if promote benefits and burden of EBF, EICF to the community, and also is implemented properly (11).

To avert the problem infants should be exclusively breastfed for the first six months of life to achieve optimal growth, development and health as a global public health recommendation (14). In addition; the global nutrition target is to increase the rate of EBF in the first six months up to at least $50 \%$ by 2025 . The purpose of this policy brief is to increase attention, to investment, and action for a set of cost-effective interventions 
and policies that can help member states and their partners in improving EBF rates among infants less than six months (6).

To strengthen the effort in reducing child mortality, Ethiopian Ministry of Health had targeted an increase proportion of exclusively breastfed infants under age 6 months $52-72 \%$ by $2019 / 2020$ as one strategy to improve child health (15). To achieve such plan data related to NEBF and factors associated is necessary. But, limited studies have been conducted at community level regarding to prevalence and associated factors of NEBF in Ethiopia; particularly in the study area. Therefore, this study was assessed the prevalence of NEBF and its factors in the first 6-months life of infants in Debre Tabor Town, Northwest Ethiopia. 


\section{METHODS}

\section{Study Area and Period}

This study was conducted in Debre Tabor Town. Which is located at a distance of 666 $\mathrm{km}$ from the capital city of Addis Ababa to the North direction of Ethiopia. Based on the information from Debre Tabor Town administrative bureau, the town has 6 urban kebeles and with an estimated total population of 84,382 with 36,285 households. Of them 19,898 in reproductive age (15-49) group. There are 11,429 under five children in the town. Among them infants aged less than 12 months are 2,628 and 2,068 are aged from 6 to 12 months. Debretabour Town has one General hospital, three health centers and six private clinics and has two health extension workers in each health center(kebele) (16). The study was conducted from March $1^{\text {st }}-30^{\text {th }}, 2019$.

\section{Study design and participants characteristics}

Community based cross sectional quantitative study was conducted. All mother-child pairs from 6-12 months in Debretabour town considered as a source population, and study population was selected/sampled/ mother-child pairs from 6-12 months in Debre Tabor Town who full fill the inclusion criteria. All biological mother-child pairs aged 6-12 months in Debretabour town were included. However, Mothers who were mentally/severely ill (not able to give breast milk due to mastectomy, unable to respond, could not talk or hear due to disability), and HIV-positive mothers who chooses to replacement feed were excluded from the study.

\section{Operational Definition}

Non-exclusive breast feeding is giving infants other foods or fluids in addition to the breast milk other than drugs, vitamins, and minerals to infants before the age of six months $(1,2,17)$.

Good knowledge on infant feeding before 6 months: Four knowledge questions were asked, and those having scored $\geq$ mean (2.51) by categorizing the mothers as having Good knowledge, and 
Poor knowledge on infant feeding before 6 months: Four knowledge questions were asked, and those having scored less than the mean (2.51) were classified as having poor knowledge $(3,17)$.

Early initiation of breast feeding: is infants breastfed within one hour of birth (14).

\section{Sample size determination and sampling procedure}

The sample size is determined using a single population proportion formula using the proportion of NEBF $47.5 \%$ in a study conducted in Gondar Town (2) with 95\% confidence interval and precision level of $5 \%$.

$$
\mathrm{ni}=\frac{(\mathrm{Z} \alpha / 2) 2 \mathrm{p}(1-\mathrm{P})}{\mathrm{d}^{2}}=\frac{(1.96) 2 * 0.475(1-0.475)}{0.05^{2}}=384
$$

Where $\mathbf{n}=$ Sample size needed

$\mathbf{z}=$ Standard normal variable at 95\% confidence level (1.96)

$\mathbf{p}=$ the prevalence of NEBF in Gondar Town (0.475)

$\mathbf{d}=$ Margin of error $(0.05)$

$\mathbf{Z} \mathbf{\alpha} / \mathbf{2}=$ Value of standard normal distribution corresponding to significant level of alpha $(\alpha) 0.05$ which is 1.96 .

$\mathrm{DE}=$ Design Effect $=2$ (due to cluster sampling technique was used)

Adding $10 \%$ nonresponse rates the final sample size for objective one was 844 . But, 2 Kebeles were included all samples taken, so total sample size became 860 . After calculating sample for different factors the larger sample size for the study was 860 (Table-1).

Cluster sampling was used to take the appropriate sample. Then two clusters were selected randomly by lottery method. 
Variables of the Study

Dependent Variable

Non-exclusive breast feeding within the first 6 months.

Independent Variables

Socio-demographic and economic characteristics:-

Age of the mothers, sex of infants, age of infants, ethnicity of the mothers, sex of the infant's, family size, utilization of family planning, marital status of the mothers, religion of mothers, number of under five children, husbands occupation, educational status mothers, mother's occupation, husbands education status, family monthly income.

\section{Maternal obstetric and health care service related:-}

ANC follow up, mothers counseled at ANC, delivery attendance, place of delivery of last child, PNC follow up, mothers counseled at PNC, maternal illness during postpartum period, total number of children (now).

\section{Knowledge and pattern of non-exclusive breast feeding:-}

Knowledge of CF time, source of information, heard information, method of feeding, type of $\mathrm{CF}$, reasons of EICF, know colostrum feeding, given colostrum, reasons discarding colostrum, EBF prevent disease ,time of initiation of BF , given mashed/fluid, time to offer the child additional diet besides breast milk ,and mother's knowledge on infant feeding.

\section{Data Collection tools and techniques:}

\section{Data collection tools}

Data was collected using a pre-tested and structured interviewer-administered questionnaire, which was adapted from $\mathrm{WHO}$ and published articles with some modifications to the local context $(1-3,6,10,14,18)$. The questionnaire was prepared in 
the English version and it translated to the local language (Amharic which was used to collect the data). The questionnaire has thirty seven questions and three parts: sociodemographic and economic characteristics assessment status, maternal obstetric and health care service related assessment, and knowledge and pattern of non-exclusive breast feeding before 6 months factors

\section{Data collection techniques}

A total of four BSc nurses as data collector and two BSc nurses as a supervisor (who have an experience of data collection) were selected. After briefly presenting the study purpose and getting oral consent from each mother with an eligible infant, data collectors interviewed participants.

\section{Data quality control}

The quality of the data was assured by pre-testing the questionnaire on $5 \%$ of the sample (43 mothers with an eligible infant) in Woreta town prior to the start of the actual study to test the fitness of the questionnaire for the study settings. Training about the data collection tool as well as data collection procedures (ways of approaching the eligible mothers and how to obtain permission for an interview) was given to data collectors and supervisors for a total of two days prior to the data collection process.

The objectives of the study were clearly explained to the data collectors as well as supervisors. The respondents were given brief orientation before they are interviewed and supervision was done at the spot by the supervisors. Throughout the course of the data collection, interviewers was supervised at each site, regular meetings was held between the data collectors, supervisor, and the principal investigator to discuss the problem arising in each interview, and detailed feedback was provided to the data collectors.

In addition, the collected data was checked daily for its completeness, accuracy, and clarity by supervisors. The principal investigator checked every questionnaire before data entry. Data was kept in the form of a file in a private secured place. 


\section{Data processing and analysis}

After checking the completeness of the data, it was entered into Epi info version 7.2.0.1, and then; it was exported to SPSS Version 20 for analysis. Descriptive analysis was done by computing proportions and summary statistics. The association between each independent variable and the outcome variable was assessed by using binary logistic regression. All variables with $P \leq 0.2$ in the bivariate analysis were included in the final model of multivariable analysis in order to control all possible confounders.

Adjusted odds ratio along with $95 \% \mathrm{Cl}$ were computed and $\mathrm{P}$-value $\leq 0.05$ was considered to declare factors that have statistically significant association with NEBF by using multivariable analysis in the binary logistic regression. The goodness of fit was tested by Hosmer-Lemeshow statistic test. Finally; the result is presented in the form of texts, tables and graphs. 


\section{ETHICAL CONSIDERATION}

Ethical clearance was obtained from the ethical review committee of school of Nursing, University of Gondar, College of Medicine and Health Sciences. Then, the participants of the study were informed about the purpose of the study, the importance of their participation, and their right to withdraw at any time. Verbal informed consent was obtained prior to data collection, and then from volunteer mothers collects the data. Mothers who practice NEBF during the data collection period were advised regarding to infant feeding. 


\section{RESULTS}

\section{Socio-demographic and economic characteristics of the study population}

A total of 860 mothers of children age between 6-12 months old were included in the study and interviewed that gave the response rate of the study $100 \%$. The mean age of the mothers was 31.1 years (S.D \pm 5.4 ). Regarding to their child, 527 (61.3\%) were 6-9 years, and 485 (56.4\%) were female. Majority of the respondents were from Amhara 843 (98.0\%) in ethnicity, and 806 (93.7\%) were orthodox Christian. Eight hundred fourteen (94.7\%) were married. Around $551(64.1 \%)$ of mothers had an educational level of secondary and above, while $544(63.2 \%)$ of husbands had educational level of secondary and above. Regarding to mothers occupational status, $264(30.7 \%)$ were house wife, and $418(48.6 \%)$ of their husbands were governmental employee (Table-2).

\section{Obstetric and health care related factors of the participants}

Of all study participants, mothers were 542 (63.0\%) had 1-2 number of children (now). Six hundred ten (70.9\%) had ANC follow up, and nearly half of mothers 409 (67.0\%) were informed about CF during their ANC. Five hundred twenty Three (60.8\%) delivered their last child at governmental hospital, and 519 (60.3\%) were delivered by nurses/midwifery. Six hundred fourty five $(75.0 \%)$ of the mothers were attended PNC, and $408(63.3 \%)$ mothers counseled about CF during their PNC visit. Six hundred fifteen $(71.5 \%)$ mothers following last delivery don't have illness during postpartum period (Table-3). 


\section{Knowledge and pattern of non-exclusive breast feeding}

Among study participants, 628 (73\%) knew colostrum feeding, 531 (84.6\%) mothers gave colostrum feeding for their recent child. Among mothers who discarded colostrum, $59(60.8 \%)$ of them responded that it was not good to feed their infants.

Four hundred thirty five (50.6\%) mothers responded as they initiated BF after one hour, and $533(62 \%)$ of mothers responded that EBF can prevent disease.

Six hundred fourty two $(74.7 \%)$ of participants heard information regarding to $\mathrm{CF}$, and the sources of information about CF, 316 (49.2\%) of mothers were from health professionals.

In the Appropriate time to introduce complementary food for the child, $350(40.7 \%)$ mothers response at 6 months, and $123(36 \%)$ mothers offer the child additional diet besides breast milk at 4-6 months.

The data revealed that mothers' reasons practiced NEBF, as they considered 166 (48.5\%) breast milk is not enough for the baby (Figure-3). Among the study participants, 154 (45.0\%) mothers provided powder milk (Figure-4), and in feeding utensils of mothers who practiced NEBF, 204 (59.6\%) used cup and spoon.

The overall knowledge of mothers on infant feeding before 6 months (knowledge questions which were know colostrum feeding, time to initiation of BF, EBF prevent disease, and appropriate time to introduce CF for the child) were calculated based on mean value by giving 0 for non-correct answers and 1 for correct answers of for all the four knowledge questions. The mean value was 2.51 by categorizing the mothers as having poor knowledge those who score less than 2.51, and good knowledge those who score of mean $\geq 2.51$. Based on this $55.3 \%$ mothers had good knowledge, and the rests had poor knowledge on infant feeding before 6 months (Table- 4). 


\section{Prevalence of non-exclusive breast feeding}

The results of the study revealed that about 342 (39.8\%) (95\% Cl: 36.6-43.0) of Debre Tabor Town mothers practiced NEBF to their infants during the first 6 months of age.

\section{Factors associated with non-exclusive breast feeding}

In order to determine factors associated with NEBF logistic regression analysis was used. On Bivariate analysis Variables having statistically significantly association between NEBF, and $p$-value ( $P \leq 0.2)$ were mother's occupational status, ANC follow up, PNC follow up, husband's educational status, husband's occupational status, mother's age, and mothers knowledge on infant feeding. However, in multivariable analysis mothers whose husbands, who had no formal education [AOR (95\% $C I)=6.60(4.14,10.410)$, and Primary education [AOR $(95 \% \mathrm{Cl})=4.30(2.62,7.20)]$, maternal occupation, governmental employed ((AOR=8.20 [(95\% Cl: 5.191, 12.940]), and daily laborer $(\mathrm{AOR}=1.70[95 \% \mathrm{Cl}: 1.01,2.90]$, merchant $(\mathrm{AOR}=0.44[95 \% \mathrm{Cl}$ : $0.35,0.90])$ and mothers who had no PNC follow up for their current child in health service $(A O R=2.40[(95 \% \mathrm{Cl}: 1.56,3.76])$ were remained significantly associated with the outcome variable with at $95 \% \mathrm{Cl}$ and $\mathrm{P}$ - value of $\leq 0.05$ (Table-5). 


\section{DISCUSSION}

This study showed that $39.8 \%$ (95\% Cl: $36.6-43.0)$ of mothers in Debre Tabor Town practiced NEBF for their infants within the first six months of age. This finding was in line with A study conducted in Jimma Arjo (42.9\%) (8), A research conducted in Maharashtra, India (42.7\%) (19), and A study in Pokhara, Nepal (40.3\%) (20).

However, the result of this study was much lower than the study done in Gondar Town, Northwest, Ethiopia (47.5\%) (2). The possible explanation for the different could be study setting which done in Gondar was both urban and rural area. A study report in Sorro District, Southern Ethiopia (49.4\%) (10). Study conducted at Kamba Woreda, South West Ethiopia (59.6\%) (11). Another study done in Jimma Arjo Woreda, Southwest Ethiopia (52.1\%) (21). All the above studies the possible justification for the different could be studies setting which were done only rural area.

Also this study was much lower than the study done in Saudi Arabia (62.5\%) (22). The study conducted in machakos district, Kenya (52\%) (12). A study at Iranshahr, Iran (76.9\%) (4). The result from a study of Peninsular, Malaysia (45.8\%) (23).

The possible explanation for the highest prevalence in (Saudi Arabia, Kenya, Iran, Malaysia) could be the study design used, which were institutional based crosssectional, among mothers who were admitted for mildly wasted infants which may increase use of additional diet; and the majority of respondents believed that an appropriate time for introducing complementary foods was between four and six months.

This result was higher as compared with other similar studies such as on research done at kersa woreda, east Ethiopia (28.3\%) (3). The possible justification for the difference could be in kersa woreda study population selected from 6-23 months which were recall bias affect under/over the result. A study conducted in Bishoftu Town, Oromia, Ethiopia (32.9\%) (9). The possible explanation for the difference might be in Bishoftu study population selected mothers with infant aged less than six months who were attending public health facilities for penta-valent three immunizations. Might be decreased the prevalence because study subjects selected at 14 weeks. And higher 12 
than a research done in Hula District, Southern Ethiopia (13.4\%) (18). The possible justification for the difference might be due to mothers had higher knowledge of exclusive breast feeding practice (96.2\%) in the Hula District and there was NGO which was working on a program called 'alive and thrives' and highly promoting the optimal breastfeeding practice.

This study also much higher than a study done in Darjeeling, West Bengal (India) (30.3\%) (24). The possible explanation for the difference could be in India Study population selected from 6-24 months which were recall bias affect under/over the result. A study conducted in Thailand (26.4\%) (25). A study done in Australia (27\%) (26). The possible justification for the difference could be in Thailand study population selected at 12 weeks of postpartum women who attended in the clinic, and in Australia reported by age of 4 months.

In this study in multivariable analysis mothers whose husbands, who had no formal education, and Primary education, maternal occupation which were governmental employed, daily laborer, merchant, and Mothers who had no PNC follow up for their current child in health service were remained significantly associated with the outcome variable with at $95 \% \mathrm{Cl}$ and $\mathrm{P}$ - value of $\leq 0.05$.

This study showed that husband educational status had significant role on NEBF with in the first 6 months. Those mothers whose husbands had no formal education [AOR $(95 \% \mathrm{Cl})=6.60(4.14,10.410)]$, and Primary education $[\mathrm{AOR}(95 \% \mathrm{Cl})=4.30(2.62$, 7.20)] were significantly associated factors for NEBF. This finding was supported by the study done in Northwest Ethiopia which revealed that husband educational level of no formal education were 1.15 times, and primary education 3.26 times more likely to practice prelacteal feeding than those who had Secondary education and above (27). Study done at Arba Minch Zuria husband educational level which were no education $(A O R=2.92)$ and able to reading and writing $(A O R=3.08)$ were significant association with Mothers' had no knowledge of optimal BF (28). The possible Explanation that husbands who had secondary and above educational level might had better understanding towards the benefits of introducing CF timely, identification of the effects 
of NEBF before 6 months, and empowers them to defend against external interferences and pressures from traditional belief and misconception.

Maternal occupation was found to be one of those significantly associated factors of NEBF for infants during the first 6 months of age. In this study, maternal occupation, the odds of NEBF were 8.2 times higher in governmental employed ( $A O R=8.20$ [(95\% Cl: 5.191, 12.940]), and 1.7 times higher in daily laborer (AOR=1.70 [95\% Cl: 1.01, 2.90] than house wife mothers. The odds of NEBF were $56 \%$ lower than in merchant mothers compared to mothers with house wife $(\mathrm{AOR}=0.44[95 \% \mathrm{Cl}: 0.35,0.90])$.

This finding was consistent with the studies done in Gondar town, being governmental employed $(A O R=2.55)$, and Kamba Woreda, South West Ethiopia, daily laborer $(A O R=3.06)$ were more likely practice NEBF compared to house wife. And maternal occupation which was merchant $(A O R=0.84)$ consistent with the studies done in Gondar town less likely to practice NEBF to their infants before 6 months. However, a study done in Kamba Woreda, South West, Ethiopia being governmental employed (AOR=0.44) were less likely practice NEBF which was inconsistent to this study $(2,11)$. In Bishoftu Town, Oromia, Ethiopia, the odds of house wife mothers had $64 \%$ lower risk to EICF than employed mothers with [AOR $0.34(95 \% \mathrm{Cl} ; 0.21,0.55)](9)$.

The study done in Saudi Arabia consistent with this study, Employed (AOR=6.39) more likely practice EICF before 6 months compared to Not Employed (22). And study done in Indonesia working mothers $(A O R=1.45)$ were significant association with NEBF compared to non-working mothers (29). A study done in Peninsular Malaysia, mothers who have a job were 3.5 times more likely not to exclusively breastfeed compared to non-working mothers (23). The possible explanation for this association government Employed and daily laborer mother believe the child is exposed with hunger and water thrust due to lack of time to breast feed frequently. So, that they start to initiate early feeding of their child solid and semi-solid food; but this might be due to the fact that housewife mothers get to stay longer with their newborn and would not be obliged like mothers who are working to wean early to go to work, so, they may also breastfeed their newborn. 
Mothers who had no PNC follow up for their current child in health service (AOR $=2.40$ [(95\% Cl: $1.56,3.76])$ were significantly associated factor for NEBF. This finding was in agreement with study done Sorro District, Southern Ethiopia, no PNC visit after delivery (AOR=1.90) was significantly associated with NEBF (10). A study conducted in Kamba Woreda, South West Ethiopia, mothers who have no PNC follow up for their child in health service (AOR=1.64) were significantly associated factors for EICF (11). The possible explanation could be mothers who get advice to improve post-natal period visit has favorable impact on the promotion of timely initiation of CF.

\section{STRENGTHS AND LIMITATIONS}

\section{Strengths}

* The Study has used relatively larger sample size.

\section{Limitations}

* NEBF practice of mother may under/over report because mothers may not surely remember foods that child took due to recall bias.

\section{CONCLUSION}

The prevalence of NEBF among mother-infant pairs of 6-12 months in Debre Tabor Town, Northwest, Ethiopia, was found to be high as compared to national and global infant and young child feeding guidelines. However; it shows improvement as compared with some previous studies in Ethiopia. Mothers whose husbands, who had no formal education, and Primary education, maternal occupation which were governmental employed, daily laborer, merchant, and those mothers who had no PNC follow up for the current child in health service institutions were factors associated with NEBF within the first 6 months in Debre Tabor Town.

\section{RECOMMENDATIONS}

\section{To health personnel/HEWs}


Advice Mothers who work outside home adopt workplace BF practices and EBM in cup to feed the child at home when they move outside home.

* Shall advice mothers to improve post-natal period follow up.

\section{To woreda health office}

* In government institution establishing baby center is an alternative solution to improve timely initiation of CF for government employed mothers.

* Collaborate with regional and national health office to develop policies on increasing the annual leave for delivered mothers to be 6 months that encourages feed their baby exclusively.

* Improve awareness of husbands who had no formal education and primary education towards the benefits of introducing CF timely.

\section{To the researchers}

* It is better if qualitative study is conducted to identify the root causes of a health problem, and to understand deeply socio-cultural and behavioral related factors.

\section{Abbreviation:}

ANC: Antenatal Care, BF: Breast Feeding, CF: Complementary Feeding, DALY: Disability-Adjusted Life-Years, EBF: Exclusive Breast Feeding, EBM: Expressed Breast Milk, EDHS: Ethiopian Demographic and Health Survey, EICF: Early Initiation of Complementary Feeding, EMOH: Ethiopian Ministry of Health, HIV/AIDS: Human Immunodeficiency Virus/Acquired Immunodeficiency Syndrome, IYCFP: Infant and Young Child Feeding Practice, NEBF: Non-Exclusive Breast Feeding, NGO: NonGovernmental Organization, PNC: Postnatal Care, SPSS: Statistical Package for Social Science, WHO: World Health Organization, UNICEF: United Nations Children's Fund. 


\section{Declarations}

Ethical approval and consent to participate: Ethical clearance was obtained from the ethical review committee of school of Nursing, University of Gondar, College of Medicine and Health Sciences. Then, the participants of the study were informed about the purpose of the study, the importance of their participation, and their right to withdraw at any time. Verbal informed consent was obtained prior to data collection, and then from volunteer mothers collects the data. Mothers who practice NEBF during the data collection period were advised regarding to infant feeding.

Consent to publication: Not applicable

Availability of data and materials: Data will be available upon request from the corresponding author.

Competing interests: The authors declare that they have no competing interests.

Funding: This research didn't receive any grant from any funding agency in the public, commercial or not-for-profit sectors.

Authors' Contribution: DG, the corresponding author, worked on designing the study, training and supervising the data collectors, interpreting the result and preparing the manuscript. The co-authors namely CWK, TGW, SFT, ESC, played their role in analyzing and interpreting the result. Moreover, the co-authors wrote the manuscript. All authors were involved in reading and approving the final manuscript.

Acknowledgment: The author acknowledged co-authors, data collectors, and supervisors. The author is also deeply acknowledging Debretabour University. Last but not least, the respondents deserve sincere thanks for their kind responses. 


\section{REFERENCE}

1. Nutrition Section Program, United Nations International Children's Fund (UNICEF) New York. Infant and Young Child Feeding program guide line. May 2011.

2. Birhanu M. et al. Prevalence and Associated Factors of Nonexclusive Breastfeeding to Infants within the First 6 Months in Gondar Town, Northwest Ethiopia, 2014. Hindawi Publishing Corporation Advances in Nursing 2014; Volume 2015.

3. Egata et al. Predictors of non-exclusive breastfeeding at 6 months among rural mothers in east Ethiopia: a community-based analytical cross-sectional study .International Breastfeeding Journal. 2013;8(8).

4. Kordsalarzeh et al. Qualitative Study of Factors Affecting Non-Exclusive Breastfeeding in the First 6-Month Life of Infants and Discontinuation of Breastfeeding in Women Admitted to Iranshahr Health Centers 2018 Prensa Med Argent 2018;104(6).

5. Ogbo et al. Population attributable risk of key modifiable risk factors associated with nonexclusive breastfeeding in Nigeria Ogbo et al BMC Public Health 2018;18:247.

6. World Health Organization (WHO).Global Nutrition Targets 2025: Breastfeeding Policy Brief.

7. Ethiopia Federal. Ethiopia Demographic and Health Survey 2016 Central Statistical Agency Addis Ababa, Ethiopia. 2016.

8. Tamiru D.et al. Survey on the introduction of complementary foods to infants within the first six months and associated factors in rural communities of Jimma Arjo. International Journal of Nutrition and Food Sciences. 2013;(2):77-84.

9. Deme G.et al. Factors Associated with Early Initiation of Complementary Feeding in Bishoftu Town, Oromia, Ethiopia Open Access Library Journal. 2015;2.

10. Tadesse et al. Prevalence and associated factors of nonexclusive breastfeeding of infants during the first six months in rural area of Sorro District, Southern Ethiopia: a cross-sectional study. International Breastfeeding Journal 2016. 
11. Agedew et al. Early Initiation of Complementary Feeding and Associated Factors among 6 Months to 2 Years Young Children, in Kamba Woreda, South West Ethiopia: A Community -Based Cross - Sectional Study. J Nutr Food Sci $2014 ; 4(6)$.

12. Ndolo L. Factors Associated with introduction of complementary feeding of infants below six months, in Machakos District, Kenya. Nairobi University cabete LJBRARY. 2008.

13. Haider R.et al. Early Complementary Feeding is Associated with Low Nutritional Status of Young Infants Recovering from Diarrhoea Journal of Tropical Pediatrics June 1996;Vol. 42.

14. World Health Organization (WHO). Planning Guide for national implementation of the Global Strategy for Infant and Young Child Feeding. 2007.

15. Federal Ministry of Health. Health sector transformation plan (HSTP). October 2015.

16. Fentahun A. South Gondar zone Health Department report, 2019: unpublished. 2019.

17. Unied States Agency for International Development (USAID), Maternal and child health survival program(MCSP) Nutrition Brief Addressing Barriers to Exclusive Breastfeeding: Evidence and Program Considerations for Low- and Middle-Income Countries. Maternal and child health program. 2017.

18. Shibru.et al. Sub-Optimal Breastfeeding and Its Associated Factors in Rural Communities of Hula District, Southern Ethiopia: A Cross-Sectional Study. Ethiop J Health Sci 2018; Vol. 28(1).

19. Dawal et al. Study of Pre Lacteal Feeding Practices and its Determinants in a Rural Area of Maharashtra Scholars Journal of Applied Medical Sciences (SJAMS). 2014;2(4):1422-1427.

20. Basnet S. et al. Reasons for Early or Late Initiation of Complementary Feeding: A Study in Pokhara. Article in American Journal of Public Health. January January 2015;3(4),69-75. 
21. Tamiru et al. Sub-optimal breastfeeding of infants during the first six months and associated factors in rural communities of Jimma Arjo Woreda, Southwest Ethiopia BMC Public Health. 2012.

22. Alzaheb RA. et al. Factors Associated with the Early Introduction of Complementary Feeding in Saudi Arabia International Journal of Environmental Research and Public Health. 2016.

23. Tan KL. non-exclusive Breastfeeding among 4-Week Post-partum Mothers 11 Factors Associated with Non-exclusive Breastfeeding among 4-Week Post-partum Mothers in Klang District, Peninsular Malaysia Mal J NF15(1): 11 - 18, 2009

24. Sarkar H. et al. Factors Influencing Mothers to Initiate Early Complementary Feeding in Darjeeling, West Bengal,. Journal of Clinical and Diagnostic Research. 2013; Vol-11(10).

25. Sucharat B.et al. Rate and factors affecting non-exclusive breastfeeding among Thai women under the breastfeeding promotion program. International Journal of Women's Health. 2017.

26. Tang L.et al. Predictors of early introduction of complementary feeding: Longitudinal study Pediatrics International. 2015(126-130).

27. Tariku et al. Factors associated with prelacteal feeding in the rural population of northwest Ethiopia: a community cross-sectional study International Breastfeeding Journal 2016. 11:14

28. Tamiru et al. Maternal knowledge of optimal breastfeeding practices and associated factors in rural communities of Arba Minch Zuria. International Journal of Nutrition and Food Sciences .2013;2(3): 122-9.

29. Upul Senarath M. et al. Factors Associated With Nonexclusive Breastfeeding in 5 East and Southeast Asian Countries: A Multilevel Analysis 2013. 


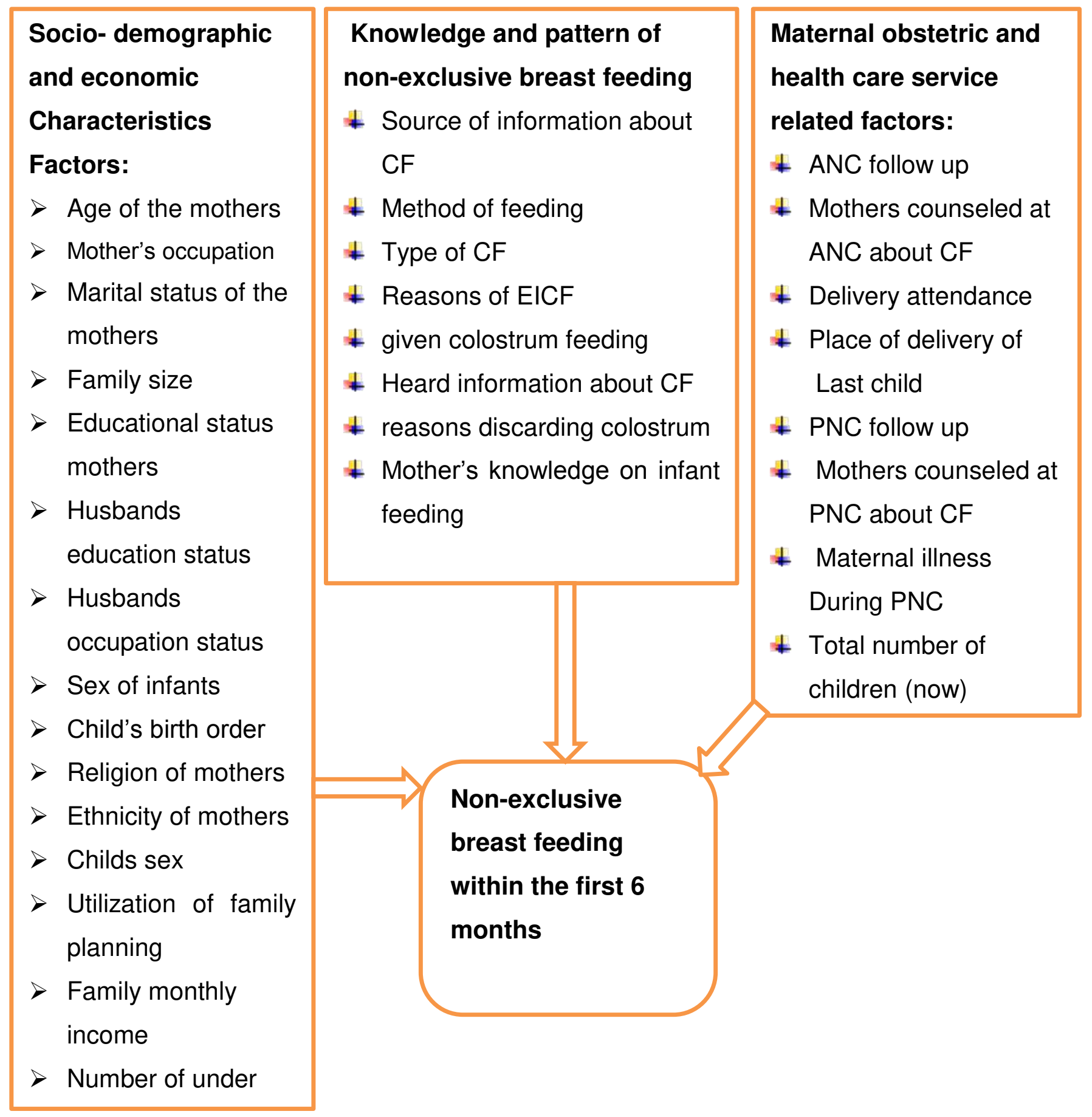

Figure 1: Conceptual framework of non-exclusive breast feeding and its factors in the first 6-month life of infants among mother-infant pairs of 6-12 months in Debre Tabor Town, Northwest, Ethiopia, 2019. 


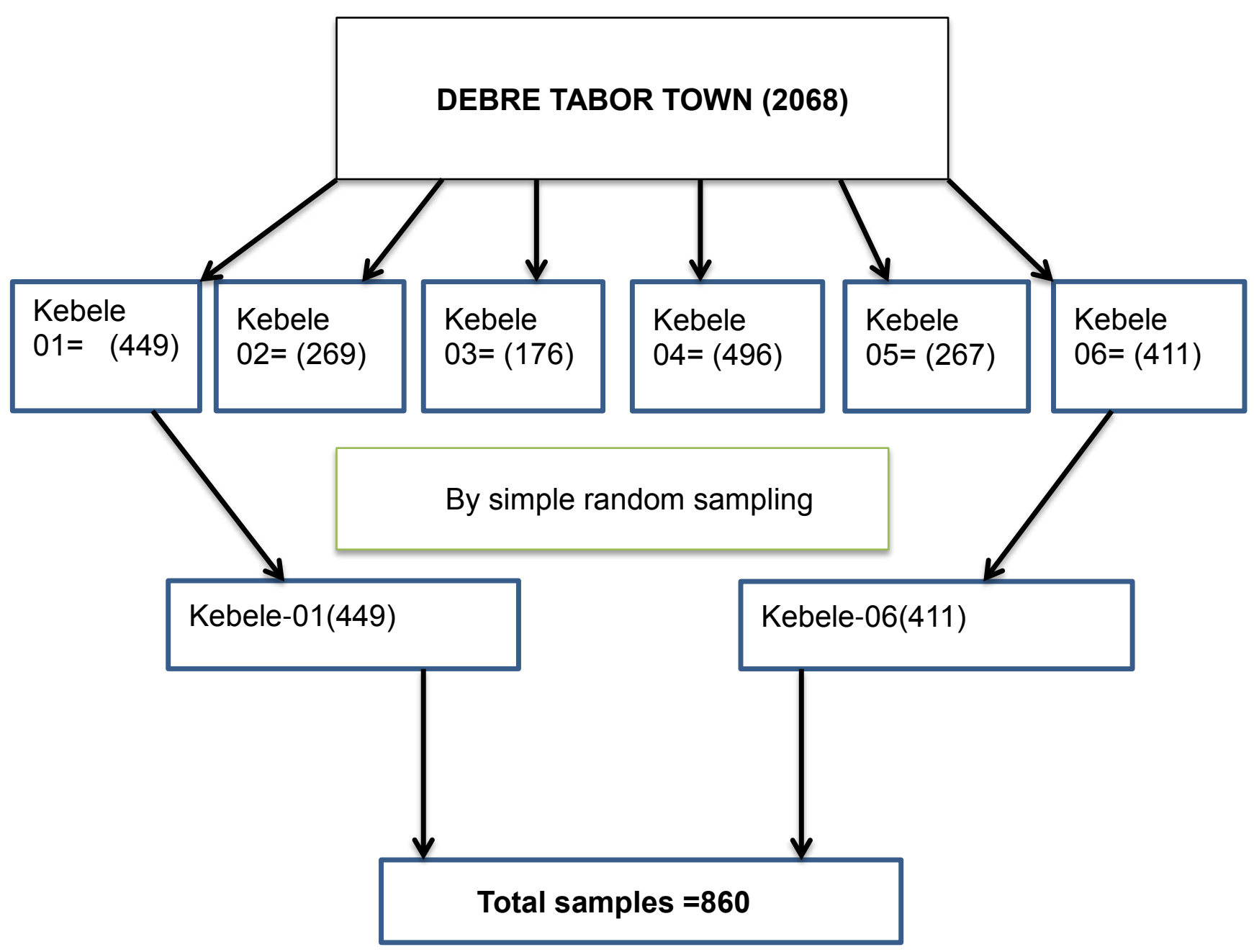

Figure 2: Schematic presentation of the sampling procedure for non-exclusive breast feeding in the first 6 month life of infants among mother-infant pairs of 6-12 months in Debre Tabor Town, Northwest, Ethiopia, 2019. 


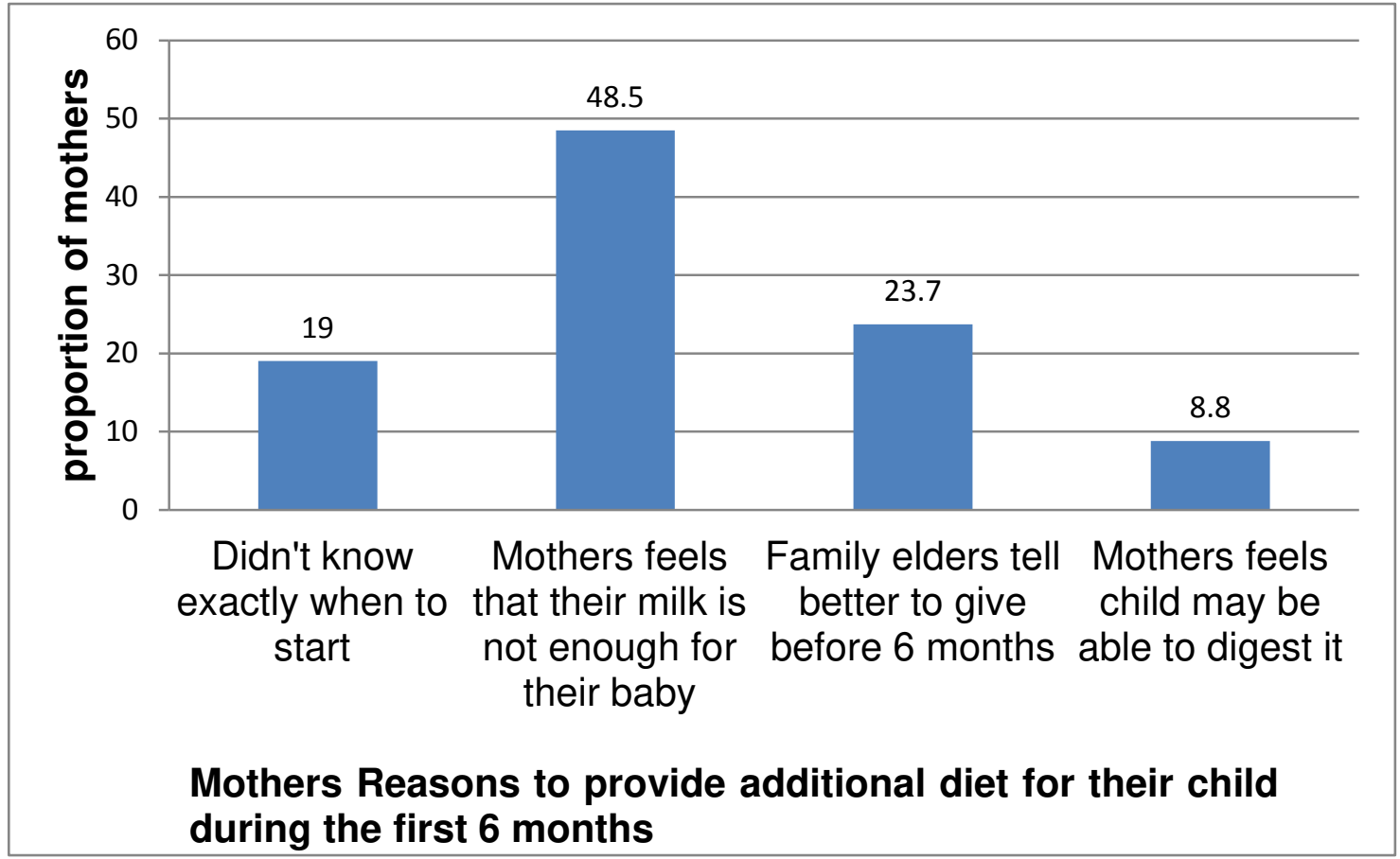

Figure 3: Mothers reasons to provide additional diet for their child during the first 6 months in Debre Tabor Town, Northwest, Ethiopia, 2019.

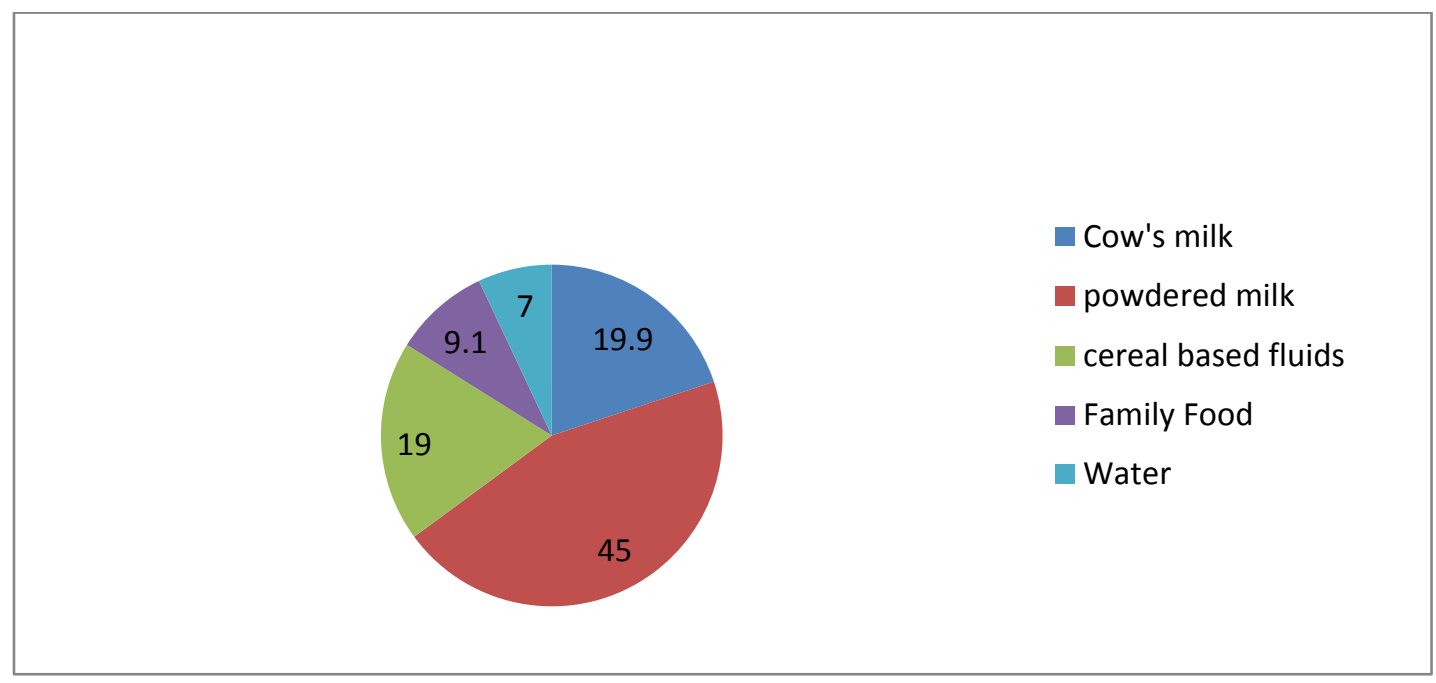

Figure 4: type of additional food mothers provides their child during the first 6 months in Debre Tabor Town, Northwest, Ethiopia, 2019 
Table 1: for the second objective identify three predictors, for non-exclusive breast feeding in Debre Tabor Town, North West Ethiopia, 2019.

\begin{tabular}{|c|c|c|c|}
\hline $\begin{array}{l}\text { Associated } \\
\text { factors }\end{array}$ & Assumption & $\begin{array}{l}\text { Final Sample size } \\
\text { with } 10 \% \text { NR and } \\
\text { Design Effect }=2\end{array}$ & Reference \\
\hline $\begin{array}{l}\text { Mother's } \\
\text { occupation }\end{array}$ & $\begin{array}{ll}\text { - } & \mathrm{Cl}=95 \%, \mathrm{AOR}=2.55, \mathrm{power}=80 \% \\
\text { - } & \text { non-exposed group }=42.7 \% \\
\text { - } & \text { exposed group }=60.8 \% \\
\text { - } & \text { Ratio } 1: 1,10 \% \mathrm{NR}\end{array}$ & 366 & (2) \\
\hline $\begin{array}{l}\text { ANC follow } \\
\text { up }\end{array}$ & $\begin{array}{l}>\mathrm{Cl}=95 \%, \mathrm{AOR}=2.60, \text { Power }=80 \% \\
>\text { non-exposed group }=67.6 \%, \\
>\text { exposed group }=36.5 \%, \\
>\text { Ratio } 1: 1,10 \% \mathrm{NR}\end{array}$ & 492 & $(10)$ \\
\hline $\begin{array}{l}\text { Time of } \\
\text { initiation of } \\
\text { BF }\end{array}$ & $\begin{array}{l}\text { Cl=95\%,AOR=2.11,Power=80\% } \\
\text { Non-exposed-group=60.5\%, } \\
\text { Exposed-group=37.5\%, } \\
\text { Ratio } 1: 110 \% \mathrm{NR}\end{array}$ & 642 & (10) \\
\hline
\end{tabular}

AOR: - adjusted odds ratio; Cl: - confidence interval, NR:-Non-Response rate

After calculating sample for different factors I found that sample sizes for the first objective was 860 [with 10\% NR and multiplying by 2 design effect] which was greater than that of the $2^{\text {nd }}$ objective; therefore the larger sample size was considered for the study. 
Table 2: Socio-demographic and economic characteristics of study participants in Debre Tabor Town, North West, Ethiopia, 2019 ( $N=860)$.

\begin{tabular}{|c|c|c|c|}
\hline Variable & category & Frequency & Percent (\%) \\
\hline \multirow[t]{7}{*}{ Maternal age } & $15-19$ & 15 & 1.7 \\
\hline & $20-24$ & 104 & 12.1 \\
\hline & $25-29$ & 202 & 23.5 \\
\hline & $30-34$ & 299 & 34.8 \\
\hline & $35-39$ & 193 & 22.4 \\
\hline & $40-44$ & 47 & 5.5 \\
\hline & $\geq 45$ & 0 & 0 \\
\hline \multirow[t]{2}{*}{ Child age } & $6-9$ & 527 & 61.3 \\
\hline & $10-12$ & 333 & 38.7 \\
\hline \multirow[t]{2}{*}{ Child sex } & male & 375 & 43.6 \\
\hline & female & 485 & 56.4 \\
\hline \multirow[t]{3}{*}{ Childs birth order } & first & 241 & 28.0 \\
\hline & second & 329 & 38.3 \\
\hline & Third and above & 290 & 33.7 \\
\hline \multirow[t]{3}{*}{ Mother's religion } & Orthodox & 806 & 93.7 \\
\hline & Muslim & 48 & 5.6 \\
\hline & Protestant & 6 & 0.7 \\
\hline \multirow[t]{3}{*}{ Mother's ethnicity } & Amhara & 843 & 98.0 \\
\hline & Oromo & 11 & 1.3 \\
\hline & Tigray & 6 & 0.7 \\
\hline \multirow[t]{4}{*}{ Marital status } & Single & 13 & 1.5 \\
\hline & Married & 814 & 94.7 \\
\hline & Divorced & 27 & 3.1 \\
\hline & Widowed & 6 & 0.7 \\
\hline
\end{tabular}




\begin{tabular}{|c|c|c|c|}
\hline \multirow{3}{*}{$\begin{array}{l}\text { Maternal } \\
\text { education }\end{array}$} & No Formal education & 125 & 14.5 \\
\hline & Primary education & 184 & 21.4 \\
\hline & Secondary education and above & 551 & 64.1 \\
\hline \multirow[t]{2}{*}{ Family size } & $<4$ & 546 & 63.5 \\
\hline & $\geq 4$ & 314 & 36.5 \\
\hline \multirow[t]{2}{*}{ FP utilization } & Yes & 487 & 56.6 \\
\hline & no & 373 & 43.4 \\
\hline \multirow{2}{*}{$\begin{array}{l}\text { Number of under } \\
\text { five children }\end{array}$} & & 710 & 82.6 \\
\hline & $\begin{array}{l}1 \\
\geq 2\end{array}$ & 150 & 17.4 \\
\hline \multirow{3}{*}{$\begin{array}{l}\text { Husband's } \\
\text { education }\end{array}$} & No-formal education & 169 & 19.7 \\
\hline & Primary education & 147 & 17.1 \\
\hline & Secondary education and above & 544 & 63.2 \\
\hline \multirow{5}{*}{$\begin{array}{l}\text { Mother's } \\
\text { occupation }\end{array}$} & Governmental employee & 241 & 28.0 \\
\hline & Farmer & 0 & 0 \\
\hline & Merchant & 233 & 27.1 \\
\hline & Daily laborer & 122 & 14.2 \\
\hline & House wife & 264 & 30.7 \\
\hline \multirow{4}{*}{$\begin{array}{l}\text { Husband's } \\
\text { occupation }\end{array}$} & Government employee & 418 & 48.6 \\
\hline & Farmer & 0 & 0 \\
\hline & merchant & 324 & 37.7 \\
\hline & Daily laborer & 118 & 13.7 \\
\hline \multirow{4}{*}{$\begin{array}{l}\text { Family income of } \\
\text { family }\end{array}$} & $<500 \mathrm{ETB}$ & 0 & 0 \\
\hline & 500-1000ЕTB & 7 & 0.8 \\
\hline & 1000-1500ETB & 22 & 2.6 \\
\hline & $\geq 1500$ ETB & 831 & 96.6 \\
\hline
\end{tabular}


Table 3: Obstetric and health care related factors of participants in Debre Tabor Town, Northwest, Ethiopia, 2019.

\begin{tabular}{|c|c|c|c|}
\hline Variable & category & Frequency & Percent (\%) \\
\hline \multirow[t]{3}{*}{ Number of Children } & $1-2$ & 542 & $63.0 \%$ \\
\hline & $3-4$ & 263 & 30.6 \\
\hline & $\geq 5$ & 55 & 6.4 \\
\hline \multirow[t]{2}{*}{ Antenatal care } & yes & 610 & 70.9 \\
\hline & no & 250 & 29.1 \\
\hline Informed CF at ANC & yes & 409 & 67.0 \\
\hline \multirow[t]{2}{*}{ Visit } & No & 201 & 33.0 \\
\hline & Home & 0 & 0 \\
\hline \multirow{4}{*}{$\begin{array}{l}\text { Place of birth For last } \\
\text { child }\end{array}$} & Gov'tal Hosp. & 523 & 60.8 \\
\hline & Gov'tal HC & 327 & 38.0 \\
\hline & Gov'tal HP & 0 & 0 \\
\hline & Private clinic & 10 & 1.2 \\
\hline \multirow{5}{*}{$\begin{array}{l}\text { Delivery attendance } \\
\text { For last child }\end{array}$} & Doctor & 341 & 39.7 \\
\hline & Nurse/midwife & 519 & 60.3 \\
\hline & HEW & 0 & 0 \\
\hline & TBA & 0 & 0 \\
\hline & Relative/friend & 0 & 0 \\
\hline \multirow{2}{*}{ Attended PNC } & yes & 645 & 75.0 \\
\hline & no & 215 & 25.0 \\
\hline \multirow{2}{*}{$\begin{array}{l}\text { Counseled about CF } \\
\text { at PNC Visit }\end{array}$} & yes & 408 & 63.3 \\
\hline & no & 237 & 36.7 \\
\hline \multirow{2}{*}{$\begin{array}{l}\text { Mothers had illness } \\
\text { during post-partum } \\
\text { period }\end{array}$} & no & 615 & 71.5 \\
\hline & yes & 245 & 28.5 \\
\hline
\end{tabular}


Table 4: Knowledge and Pattern of non-exclusive breast feeding related factors of participants in Debre Tabor Town, Northwest, Ethiopia, 2019.

\begin{tabular}{|c|c|c|c|}
\hline Variable & Category & requency & Percent (\%) \\
\hline \multirow[t]{2}{*}{ know colostrum feeding } & no & 232 & 27.0 \\
\hline & yes & 628 & 73.0 \\
\hline \multirow[t]{2}{*}{ Given colostrum feeding } & no & 97 & 15.4 \\
\hline & Yes & 531 & 84.6 \\
\hline \multirow[t]{2}{*}{ Reason discarding colostrum } & Not good for infant & 59 & 60.8 \\
\hline & Due to illness & 38 & 39.2 \\
\hline \multirow[t]{2}{*}{ Time to initiation of BF } & After one hour & 435 & 50.6 \\
\hline & Within one hour & 425 & 49.4 \\
\hline \multirow[t]{2}{*}{ EBF prevent disease } & no & 327 & 38.0 \\
\hline & Yes & 533 & 62.0 \\
\hline \multirow[t]{2}{*}{ Heard information to CF } & no & 218 & 25.3 \\
\hline & Yes & 642 & 74.7 \\
\hline \multirow[t]{4}{*}{ Source of information to CF } & Radio & 75 & 11.7 \\
\hline & Television & 133 & 20.7 \\
\hline & $\mathrm{CHW}$ & 118 & 18.4 \\
\hline & HP & 316 & 49.2 \\
\hline \multirow{3}{*}{$\begin{array}{l}\text { Appropriate time to introduce CF } \\
\text { for the child }\end{array}$} & $=$ Before 6 month & 290 & 33.7 \\
\hline & At 6 month & 350 & 40.7 \\
\hline & After 6 month & 220 & 25.6 \\
\hline \multirow{7}{*}{$\begin{array}{l}\text { Give mashed or fluid to child } \\
\text { During the first } 6 \text { months } \\
\text { Offer the child additional diet } \\
\text { besides breast milk }\end{array}$} & no & 518 & 60.2 \\
\hline & yes & 342 & 39.8 \\
\hline & Before 4 month & 66 & 19.3 \\
\hline & At 4-6 months & 123 & 36.0 \\
\hline & At 6 months & 11 & 3.2 \\
\hline & Late after 6 months & 32 & 9.4 \\
\hline & I don't know & 110 & 32.1 \\
\hline
\end{tabular}




\begin{tabular}{|c|c|c|c|}
\hline \multirow[t]{4}{*}{ Reasons to provide additional diet } & Didn't know exactly when to start & 65 & 19.0 \\
\hline & $\begin{array}{l}\text { Mothers feels that their milk is } \\
\text { not enough for their baby }\end{array}$ & 166 & 48.5 \\
\hline & $\begin{array}{l}\text { Family elders tell better to give } \\
\text { before } 6 \text { months }\end{array}$ & 81 & 23.7 \\
\hline & $\begin{array}{l}\text { Mothers feels child may be } \\
\text { able to digest it }\end{array}$ & 30 & 8.8 \\
\hline \multirow[t]{5}{*}{ Additional food mother's provide } & Cow's milk & 68 & 19.9 \\
\hline & Powdered milk & 154 & 45.0 \\
\hline & Cereal based fluids & 65 & 19.0 \\
\hline & Family food & 31 & 9.1 \\
\hline & Water & 24 & 7.0 \\
\hline \multirow{4}{*}{ use to give the fluids with (utensils) } & Bottle nipple & 56 & 16.4 \\
\hline & Cup and spoon & 204 & 59.6 \\
\hline & Both bottle and & & \\
\hline & Cup and spoon & 82 & 24.0 \\
\hline \multirow{2}{*}{$\begin{array}{l}\text { Mothers knowledge } \\
\text { on infant feeding }\end{array}$} & Poor & 384 & 44.7 \\
\hline & Good & 476 & 55.3 \\
\hline
\end{tabular}


Table 5: Factors associated with non-exclusive breast feeding before 6 months, in Debre Tabor Town, Northwest Ethiopia, 2019.

\begin{tabular}{|c|c|c|c|c|c|c|}
\hline \multirow[t]{2}{*}{ Variable } & \multirow[t]{2}{*}{ category } & \multicolumn{2}{|c|}{ NEBF within6 months } & \multirow[t]{2}{*}{$\operatorname{COR}(95 \% \mathrm{Cl})$} & \multirow[t]{2}{*}{$\mathrm{AOR}(95 \% \mathrm{Cl})$} & \multirow[t]{2}{*}{$p-v$} \\
\hline & & Yes n (\%) & No n (\%) & & & \\
\hline \multirow{8}{*}{$\begin{array}{l}\text { Husband's } \\
\text { education }\end{array}$} & No-formal & $98(58.0)$ & $71(42.0)$ & $3.12(2.18,4.45)$ & $6.6(4.14,10.41)$ & .000 \\
\hline & education & & & & & \\
\hline & Primary & $77(52.4)$ & $70(47.6)$ & $2.48(1.71,3.60)$ & $4.3(2.62,7.20)$ & .000 \\
\hline & education & & & & & \\
\hline & Secondary & $167(30.7)$ & $377(69.3)$ & 1 & 1 & \\
\hline & education & & & & & \\
\hline & and & & & & & \\
\hline & above & & & & & \\
\hline \multirow{6}{*}{$\begin{array}{l}\text { Mother's } \\
\text { occupation }\end{array}$} & Gov'tal & $150(62.2)$ & 91(37.8) & $4.15(2.90,6.03)$ & $8.20(5.19,12.94)$ & .000 \\
\hline & employee & & & & & \\
\hline & Merchant & $61(26.2)$ & $172(73.8)$ & $0.89(0.60,1.33)$ & $0.44(.35, .90)$ & .017 \\
\hline & Daily & $56(46.0)$ & $66(54.0)$ & $2.14(1.37,3.34)$ & $1.70(1.01,2.90)$ & .045 \\
\hline & laborer & & & & & \\
\hline & House wife & $75(28.4)$ & 189(71.6) & 1 & 1 & \\
\hline \multirow{4}{*}{$\begin{array}{l}\text { Husband's } \\
\text { occupation }\end{array}$} & Gov'tal & $151(36.1)$ & $267(63.9)$ & $0.743(0.49,1.13)$ & & \\
\hline & employee & & & & & \\
\hline & Merchant & $140(43.2)$ & $184(56.8)$ & $1.000(.65,1.53)$ & & \\
\hline & Daily laborer & $51(43.2)$ & $67(56.8)$ & 1 & & \\
\hline ANC & no & $134(53.6)$ & $116(46.4)$ & $2.23(1.65,3.01)$ & & \\
\hline Follow up & yes & $208(34.1)$ & 402(65.9) & 1 & & \\
\hline PNC & no & $132(61.4)$ & $83(38.6)$ & $3.29(2.39,4.54)$ & $2.4(1.56,3.76)$ & .000 \\
\hline Follow up & Yes & $210(32.6)$ & $435(67.4)$ & 1 & 1 & \\
\hline
\end{tabular}




\begin{tabular}{llllc} 
Mother's & $15-19$ & $5(33.3)$ & $10(66.7)$ & $0.88(0.26,3.01)$ \\
age & $20-24$ & $38(36.5)$ & $66(63.5)$ & $1.0(0.50,2.08)$ \\
& $25-29$ & $70(34.7)$ & $132(65.3)$ & $0.94(0.48,1.81)$ \\
& $30-34$ & $119(39.8)$ & $180(60.2)$ & $1.17(0.62,2.20)$ \\
& $35-39$ & $93(48.2)$ & $100(51.8)$ & $1.64(0.85,3.20)$ \\
& $40-44$ & $17(36.2)$ & $30(63.8)$ & 1 \\
Mother & Poor & $163(42.4)$ & $221(57.6)$ & $1.2(0.93,1.61)$ \\
knowledge & good & $179(37.6)$ & $297(62.4)$ & 1 \\
$\begin{array}{l}\text { on infant } \\
\text { feeding }\end{array}$ & & & & \\
\hline
\end{tabular}

Reference $=1.00$, COR=Crude 0dds Raito, AOR=Adjusted Odds Ratio, $P V=P$-Value 


\section{Figures}

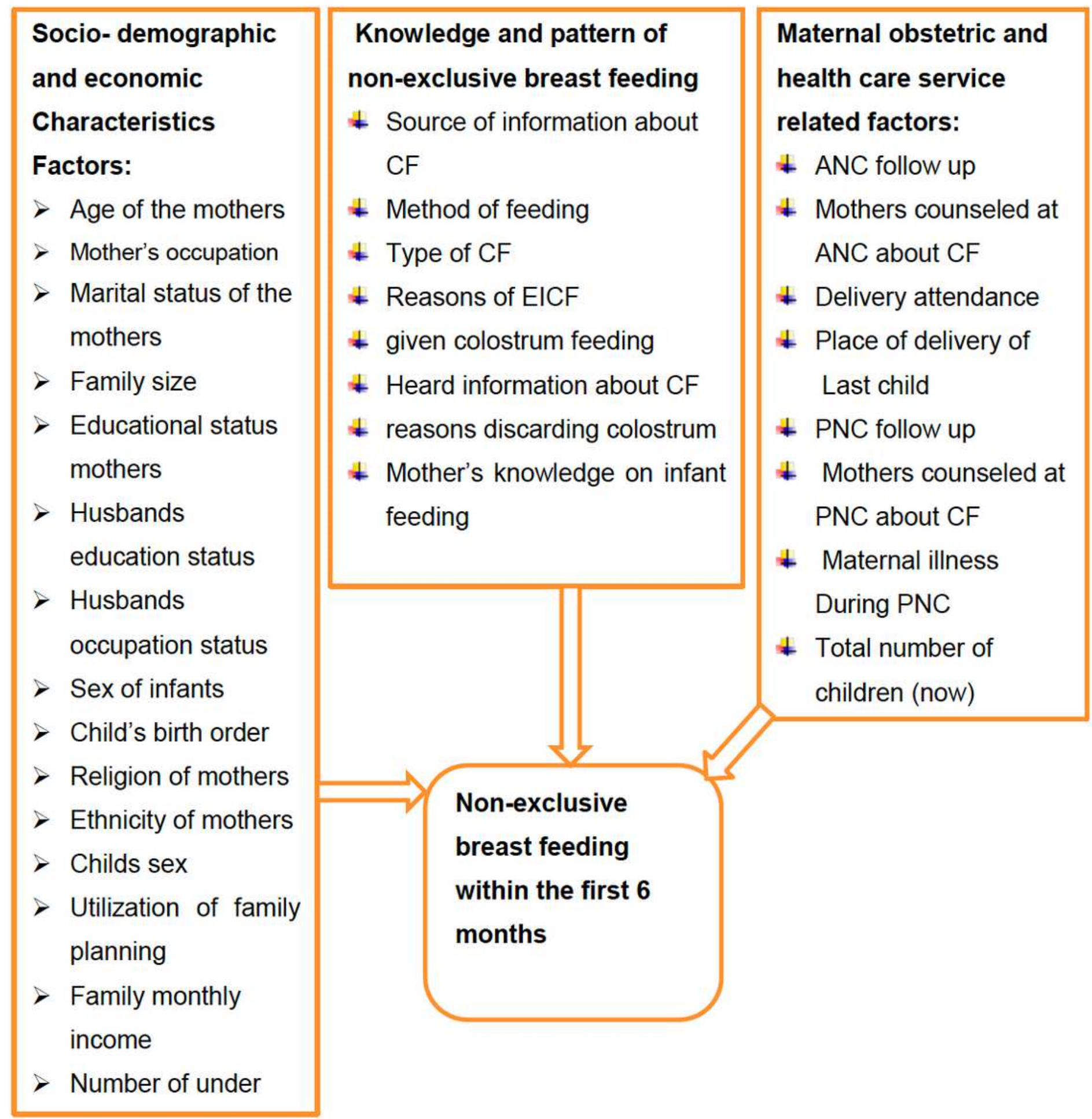

Figure 1

Conceptual framework of non-exclusive breast feeding and its factors in the first 6-month life of infants among mother-infant pairs of 6-12 months in Debre Tabor Town, Northwest, Ethiopia, 2019. 


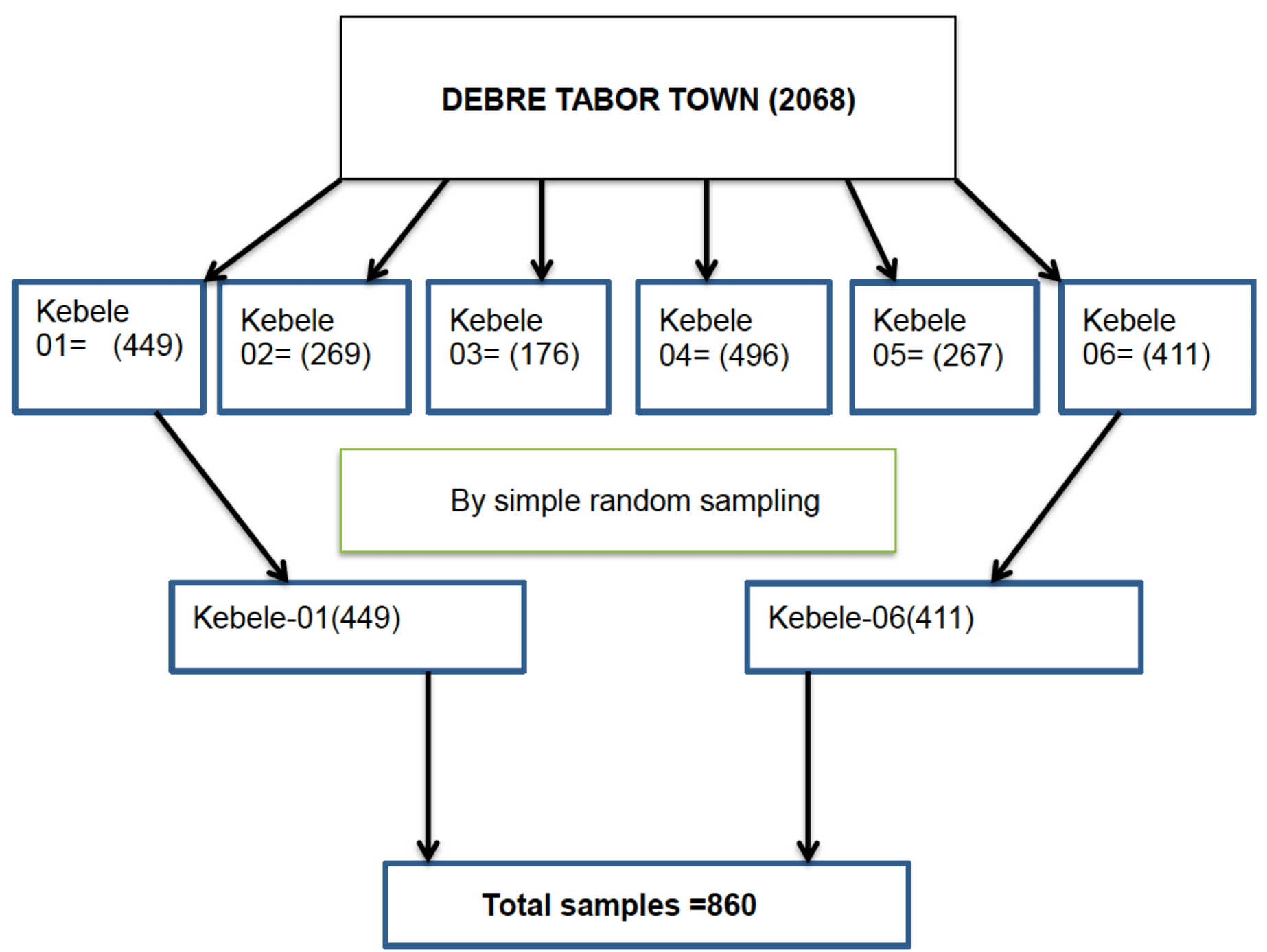

Figure 2

Schematic presentation of the sampling procedure for non-exclusive breast feeding in the first 6 month life of infants among mother-infant pairs of 6-12 months in Debre Tabor Town, Northwest, Ethiopia, 2019. 


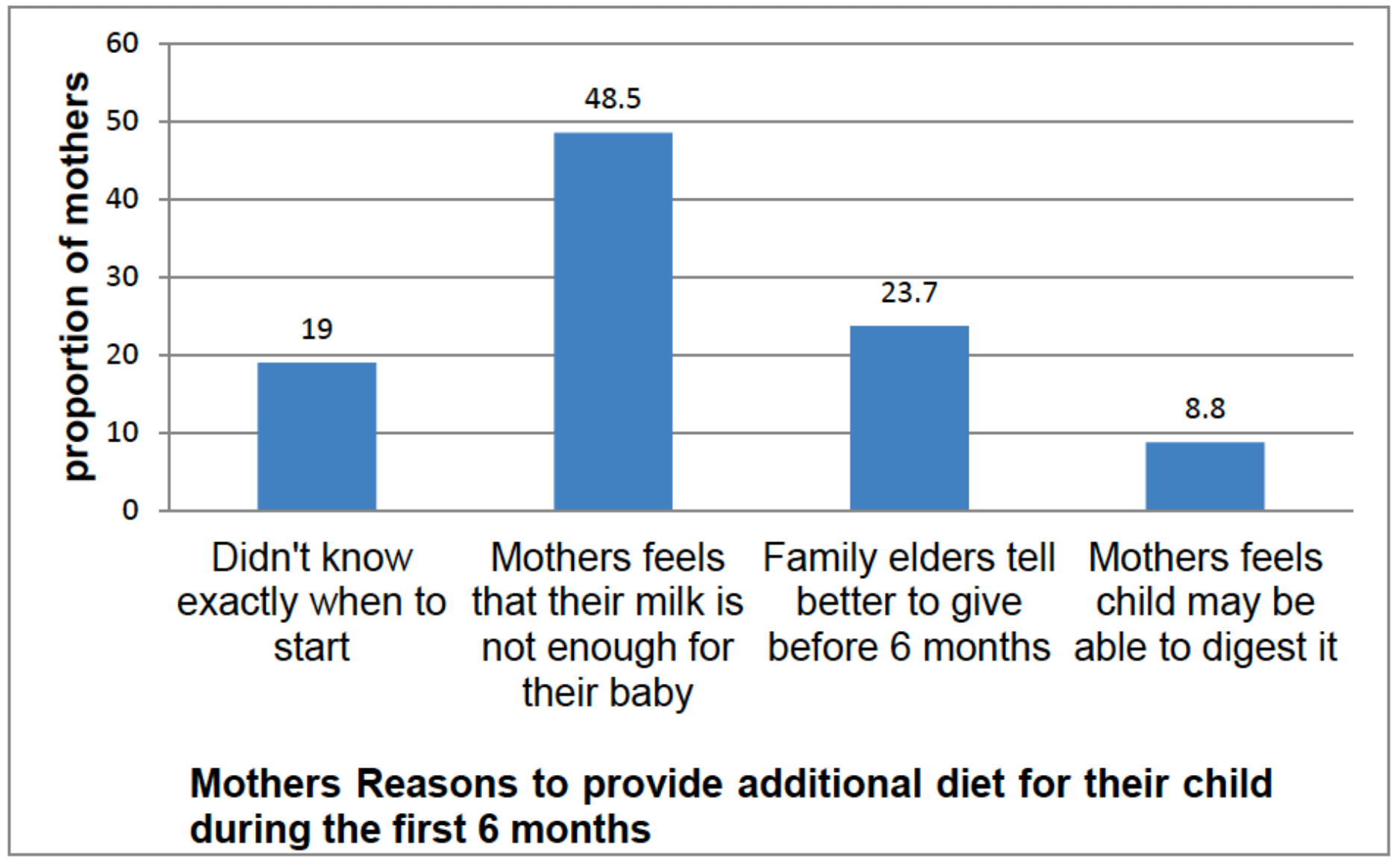

Figure 3

Mothers reasons to provide additional diet for their child during the first 6 months in Debre Tabor Town, Northwest, Ethiopia, 2019.

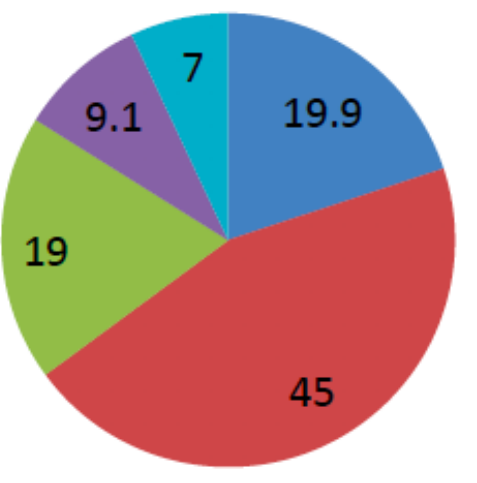

Cow's milk

powdered milk

cereal based fluids

Family Food

Water 
Figure 4

type of additional food mothers provides their child during the first 6 months in Debre Tabor Town, Northwest, Ethiopia, 2019 